\title{
A Retrospective Examination of Female Model Portrayals in Male Youth Targeted Cigarette Advertising Through the Lens of Objectification Theory
}

\author{
James Mark Mayer \\ Ball State University
}

\author{
Tae Hyun Baek \\ University of Kentucky
}

\author{
Abby Mayer \\ Drexel University \\ Plamen Peev \\ Towson University
}

\begin{abstract}
We present a retrospective (1994-2003) portrayal of female models in a decade's worth of male-targeted cigarette advertising. We specifically conduct a content analysis on cigarette manufacturer-sponsored advertisements in male-oriented print magazines. We first explore the set of advertisements using a Gestalt-type analysis, which then informs a formal content analysis using a carefully developed manual and conduct quantitative analysis on key variables that emerged. Overall, we find that the portrayal of females in male-targeted cigarette print advertising largely consists of young, objectified women whose purpose is overwhelmingly decorative, primarily to endow the advertising with sexual allure and use a "sex sells" type effort at that male audience target. These female models are used to add a hedonic, pleasure-seeking, sexual meaning to cigarette consumption, are restricted in gender role to traditional notions of femininity, and rarely appear in groups. They even are assigned different roles in terms of the simple act of smoking than males in the advertisements. We also discuss implications and areas for further research.
\end{abstract}

Keywords: Female Objectification, Sex in Advertising, Sex Portrayals, Cigarette Advertising, Content Analysis

\section{INTRODUCTION}

Historically, one of the main executional elements used in cigarette advertising has been sexual imagery, especially in advertisements targeted to men. For example, the use of this imagery in youthoriented media increased markedly even after the Tobacco Master Settlement Agreement (MSA; Baek 
and Mayer, 2010, Sung and Hennink-Kaminski, 2008). As Pollay et al. (1996) write, "the battle of the (cigarette) brands for market share is waged largely among the young, for it is a brand's success among the young that leads to greater brand sales and profit in the long term" (p. 13). The potential ethical issues of targeting youth with a product known to cause lifelong and sometimes deadly health issues including, but not limited to cancer, heart disease, and respiratory problems, are exacerbated by the use of imagery (e.g., objectifying women as decoration with limited purpose beyond sexual attractiveness) that can have deleterious effects on both the objectified group (women) and the target audience (men, in terms of how they view women).

Despite decades of extensive research into many aspects of cigarette industry's advertising efforts, our focus in this article - cigarette advertising's use of objectified female models in campaigns targeted to younger male consumers - has had limited examination to date. In this paper, we look back at the period from 1994 to 2003 to provide that perspective, extending the exploration of these advertisements beyond simply the presence of sexual themes and clothing attire (Mayer and Baek, 2015) to other variables that illustrate the holistic portrayal of females in these advertisements. We begin with a discussion of objectification theory and a brief historical review of the use of the female in male-targeted advertising.

\section{OBJECTIFICATION THEORY AND HISTORICAL FEMALE MODEL PORTRAYALS IN ADVERTISING}

Researchers have been exploring gender-based model portrayals in advertising for over four decades, and consistent trends of inequality (as compared to male portrayals) and stereotyping have emerged. Research examining advertising of the 1960s and 70s suggests that women were depicted far less frequently than men as working outside of home and making important purchases (Courtney and Lockeretz, 1971), were less likely to be portrayed as authoritative figures (McArthur and Resko, 1975), more likely to be shown as belonging at home (Courtney and Lockeretz, 1971; Courtney and Whipple, 1974; Gilly, 1988; Pingree et al., 1976), and as subordinate to (Goffman, 1976)--and dependent on (Courtney and Lockeretz, 1971; Gilly, 1988; Venkatesan and Losco, 1975)--men. Over this time period, women were also increasingly used as sexual objects in advertising (Sexton and Haberman, 1974; Venkatesan and Losco 1975).

This last trend--the use of females as sexual objects in advertising--has continued to gain momentum over time. The stereotyping of women primarily as objects of male sexual desires increased continuously starting in the early 1970 s to the point where nearly $50 \%$ of female models in advertising were sexually dressed in 2003 (Ferguson, Kreshel, and Tinkham, 1990; Reichert and Carpenter, 2004; Soley and Kurzbard, 1986), all the while the amount of sexually-themed advertising not featuring female models had leveled off, indicating that there was not simply an overall increase in the use of sex appeals across the board, but rather a growing focus on using female models in this manner (Reichert and Carpenter, 2004).

Sexual imagery was employed in cigarette advertising for hundreds of years as early as the $19^{\text {th }}$ century when advertisements and labels often featured nude women - a strategy designed to appeal to the male consumers (Reichert, 2003). The most significant surge in the use of women for purely decorative purpose in cigarette ads, however, occurred between the 1950s and 1970s (King et al., 1991, Sexton and Haberman, 1974). This trend was necessitated by the public perception that smoking is a sexually relevant activity (Reid and Soley, 1983) - a view reflected in pop-culture-defining fields such as film (e.g., Escamilla, Cardock, and Kawachi, 2000) and advertising (e.g., Schooler, Basil, and Altman, 1996). Hence, it is not a surprise that one of the enduring cigarette advertising theme is that people who smoke are popular and have high sex appeal, especially since that tactic has proven very effective when targeted to adolescents (Brown and Witherspoon, 2002; Charlesworth and Glantz, 2005; Sussman, 2005). Further, research has found that the use of sexual themes in advertising actually increased as the Master Settlement Agreement (MSA) supposedly restricted cigarette manufacturer's advertising ability; these sexual ads increased in post-MSA (versus pre-MSA) in examinations of cigarette advertising (Baek and Mayer, 
2010), and at least to some degree, appear to be efficacious in providing cigarette brands with positive advertising outcomes (Mayer and Baek, 2015).

Objectification theory provides the theoretical understanding of the importance of examining the depictions of sexual imagery in advertising (Frederickson and Roberts, 1997). It conjectures that in a culture where the female form is continually sexually objectified, the female often places high levels of importance on her physical image, which she interprets through an observer's perspective. Essentially, surrounded by an environment of sexual objectification, especially in the media, women are encouraged to self-objectify (view themselves as objects). Frederickson and Roberts (1997) reasoned that this type of internalizing of an outsider's perspective can lead to "habitual body monitoring," opening up a potential door to feelings of "anxiety and shame" (p. 173). Vandenbosch and Eggermont (2012) argued that selfobjectification usually paves the way for its "behavioral counterpart" of body surveillance or rather the "extent to which individuals behaviorally invest in the body as an object" (p. 871).

Moreover, the APA Task Force on the Sexualization of Girls (2007) maintained that depression, eating disorders and low self-esteem are connected with sexualization and self objectification. The task force also determined that girls and young women who are more frequently exposed to mainstream mass media content often buy into sexual stereotypes and think that their appearance being is most important aspect of who they are (APA Task Force, 2007).

As previously stated, sexualized and objectified females are often used in advertisements to attempt to create positive outcomes for the advertising brands with a male target audience. But the effects on this audience can extend beyond simply influencing things like consumer attitudes. Perhaps most relevant to our retrospective examination of male-targeted advertisements, objectification of females in the media has been shown to affect males' thoughts about, and behavior towards, females. For example, Malamuth (1984) argued that men were less sympathetic towards women since one of the studies demonstrated that college men actually enjoy films of a rape scene if the woman being raped was shown to come to climax during the rape. Allen, Emmers, Gebhardt, and Giery (1995) also discovered in their meta-analysis that there was a positive relationship between watching pornography and the acceptance of rape myths, especially in studies where the pornography included violence against women. These are examples of results of exposure to extreme stimuli, but they highlight the point that objectification of females can have varying degrees of negative outcomes to multiple populations.

\section{METHOD}

In order to examine objectification in these cigarette advertisements, we first specified the overall objective for our study--an examination of the extent of female objectification in model portrayals in youth male-targeted cigarette advertising. We were fortunate to have access to a census of cigarette magazine advertisements which appeared in several magazine titles from 1994-2003; these were provided by an advertising professor who had served as an expert witness during tobacco litigation. These advertisements were also successfully used in previous research (Mayer and Baek, 2015; Baek and Mayer, 2010).

Ultimately, we desired to perform a quantitative content analysis on specific content variables that we felt might provide evidence, or lack thereof, of objectification occurring. There is strong evidence in previous research that this was the case. For instance, in Mayer and Baek (2015) the authors find that when females were present in these advertisements sexual themes were more likely to be present than when males were, with female models more often "dressed suggestively relative to males" and found "(consistent) instances of females whose purpose was simply to arouse the assumed male viewer and endow the cigarette advertisement with a sexual nature" with female models more likely to be clad in

suggestive clothing than male models. The authors conclude that this suggests "deliberate inclusion of attractive, suggestively dressed females, whereas the males in the images, despite the variety of the executions ranging from traditional (a cowboy) to more trendy (a club-goer), tend to be dressed more demurely" (p. 489). While the authors don't specifically discuss the objectification of females as an outcome, it is likely that this was the case given the pervasiveness of sexual themes and nudity level that 
they find. We thus desired to supplement these findings on sexual themes and suggestive attire (which seems to indicate objectification occurring) with a further examination of other variables or dynamics that might suggest this occurrence.

In order to start the process of identifying these variables, the we initially performed a Gestalt-type analysis on approximately 200 advertisements in order to provide, as Belk writes, "a number of themes and patterns... dimensions for quantitative analysis, and...richer understanding" (1987, p. 28). In interpreting the advertisements holistically, we noticed some consistent patterns emerging as far as imagery that might contribute to overall objectification of females in these ads, including the use of sexual themes and nudity levels. Beyond these, though, we found that while it was certainly true that sexualization of females was prevalent, that other dynamics appeared to be present as well. This identification of specific variables was an important step, as researchers have suggested that multiple factors beyond just sexualization create the portrayal of women as objects in advertisements (Fasoli et al., 2018). The specific components that we noted supporting the female objectification include different dimensions of model characteristics, advertising themes present or lacking in certain advertisements, model roles, and models' interactions with cigarettes (and, concurrently, that the portrayals of women were decidedly different from those of males).

Following the qualitative content analysis, a quantitative coding scheme based on our qualitative findings was developed. Where possible, for both coding clarity and in the interest of nomological validity, we conducted a literature search and utilized or adapted variables from extant research, including research exploring sexual themes in advertising (Reichert and Carpenter, 2004; Reichert and Ramirez, 2000), gender portrayals (Baker, 2005; Ford et al. 1998), and other relevant work (Bem, 1974; Voss, Spangenberg, and Grohmann, 2003). The results of the quantitative coding process showcased the extent of female objectification occurring in these male-oriented cigarette ads. For simplicity, rather than discuss the qualitative and quantitative findings separately, we present them concurrently below. Construct definitions of all variables are found in the appendix.

\section{Sample and Coding Process}

Print advertising has historically been a highly relevant medium for cigarette manufacturers, particularly since television broadcast advertising was banned beginning January 1, 1971; for instance, the absolute spend on magazines from 1994-2003 was over \$3.3b (FTC, 2007). The two magazine titles selected as male-oriented were Rolling Stone and Sports Illustrated. We had several motivators for our selection. Both SI and RS enjoy large readership, which also skews male and relatively young; Mediamark Research Incorporated (MRI) estimates that in the fall of 2007, SI had 20.8 million readers $(79 \%$ male, median age of male reader $=38.2)$ and RS's audience was 12.1 million $(59 \%$ male, median age of male reader $=30.9)$. Both magazines fit the FDA standard of what constitutes an issue targeting youth (Sung and Hennink-Kaminski, 2008). These magazine titles have also been identified numerous times in the communications and marketing literature as appropriate units of observation for maleaudience analysis (e.g., Kolbe and Albanese, 1996). Finally, both magazines have distinctly different themes -- SI's editorial profile touts that "SI is one of the most respected sports brands in the world," while RS's profile maintains that "Rolling Stone magazine is a cultural icon. It's the number one pop culture reference point for 12 million young adults." So while both are mainstream titles, they offer inherently different positioning and subject matter, providing a more robust sample of advertisements. Our sample of cigarette advertisements from SI and RS was drawn from an existing database spanning the period between 1994 and 2003 and prepared for the Department of Justice as part of an unrelated tobacco industry litigation.

\section{Quantitative Coding Process}

The coding was completed by four graduate students majoring in advertising and public relations. All coders were students in a doctoral seminar on content analysis and all, prior to the coding, had been assigned to read a content analysis methodology text and had discussed numerous content analysis methodology-based journal articles in the doctoral classroom setting. They also received a rigorous 
training using a training manual, which featured theoretical and practical guidance for all variables present in the study. Additionally, all coders went through a two-hour in-person training session consisting of a detailed review of all variables and examples of their different levels. Coders were provided with an electronic coding sheet.

The first coding occurred in a small pilot study where all coders evaluated 30 ads from Rolling Stone from the early 1990s (outside the period covered by the main study). The level of inter-coder agreement was calculated using Perrault and Leigh's (1989) index $\left(\mathrm{I}_{r}\right)$. Following the pilot study, troublesome variables were either eliminated or revised, the training and coding manuals were improved, and an additional in-person training session was conducted.

Our representative sample of 853 advertisements $(52 \% S I, 48 \% R S)$ was designed to reflect the total ten-year catalog of ads well both in terms of the cigarette brands represented as well as the date of the issues the ads came from. The coders first verified that the images were indeed advertisements (and not cigarette-related images, for example, auto racing sponsorships pictures) by noting the presence of the mandated surgeon general's warning, and each individual independently coded a stratified sample of the advertisements consisting of between 168 and 174 unique ads, as well as 86 advertisements that one other coder also coded. Thus, 172 ads, or $20 \%$ of sample, were used in calculating inter-coder reliabilities - a percentage at the high end of methodological recommendations (Riffe, Lacy, and Fico, 1998). For our variables of interest, reliabilities ranged from 0.75 to 0.99 and were all equal to or greater than our minimum cutoff level of .75 (per Rust and Cooil, 1994).

\section{Content Analysis Findings: Model Characteristics and Roles}

\section{Presence / Number of Models}

During the qualitative review, we noted that males were often portrayed in groups of two or more and shown in a variety of social settings (e.g., cowboys working together on the ranch, buddies enjoying a night out on the town, friends eating together in a restaurant). This is unsurprising, as these portrayals would ostensibly highlight the social "fun" (e.g., male bonding) nature of smoking. While numerous ads featured three or more women, almost invariably they were accompanied by a number of men (e.g., tailgating together at a sporting event) and very rarely were they portrayed in groups without the company of men.

In terms of sexual themes interacting with this model-number choices by advertisers, seemingly much more frequently than not, females were shown individually as objects of desire. Groups of women were occasionally portrayed, but in a depreciating manner; for instance, humorous Camel ads where suggestively-clad women fought with each other over their sexual desire for a "Bigfoot" character on the set of a surreally-styled talk show.

Quantitative analyses confirmed these differences. Of the total set of 853 advertisements, $75 \%$ ( $\mathrm{n}=$ 643) featured at least one model of either gender. A chi-square test confirmed that the representation of males was significantly different from that of females $\left(\Pi^{2}(49)=728.64, p<.001\right)$. Of the total advertising set, $60 \%(\mathrm{n}=512)$ featured at least one male model and $45 \%(\mathrm{n}=387)$ - at least one female. Of the 512 ads featuring males (females), 60\% (73\%) featured one, 18\% (11\%) featured two, 5\% (7\%) featured three, and 17\% (11\%) featured four or more models. These findings suggest that in our sample, males are more likely to be represented in groups than are females. We conducted a follow-up analysis, examining advertisements that featured either only male or only female models. This analysis showed that 256 ads $(30 \%)$ featured only males, while $131(15 \%)$ featured only females. Of the $256(131)$ ads that featured only males (females), 64\% (90\%) featured one, 15\% (5\%) featured two, $4 \%$ (3\%) featured three males, and 17\% (2\%) featured four or more males. These comparisons are even more striking in their disparity. Stated simply, men are more likely to be portrayed enjoying themselves in groups than are females, especially in sole-gender portrayals.

\section{Gender Roles}

Though we did not explicitly develop hypotheses, we all did expect males to be overwhelmingly portrayed as extremely masculine (especially in terms of the stereotypically uber-male Marlboro Man and 
Joe Camel), and while these portrayals are certainly prevalent, surprisingly, male models in many cigarette advertisements (even Marlboro and Camel ads) are often shown demonstrating traditionally unmasculine behavior, such as helping others and being concerned with camaraderie. Females, on the other hand, are generally submissive to males, largely existing for their beauty and rarely shown as independent or self-sufficient. There were certainly exceptions to these gender roles, but overall male role portrayals were, figuratively speaking, painted with a broader brush than females - males could be "cool" and masculine, or "warm" and even feminine, whereas females were largely confined to traditional feminine roles suggestive of an outdated notion of a female's "place" in society.

Quantitative analyses supported this finding. In the 512 advertisements featuring males, the main male model was more likely to be classified as primarily masculine $(59 \%)$ than as any other gender classification $\left(\Pi^{2}(4)=549.66, p<.001\right)$, but in the remaining $41 \%$ of the ads they were classified differently, including as primarily feminine in $22 \%$ of the ads. Conversely, while females were also most likely to exhibit traditional roles $(75 \%)$ in the 387 ads featuring female models $\left(\Pi^{2}(4)=147.14, p<\right.$ $.001)$, they were less likely to be classified as exhibiting another gender role and rarely were primarily masculine (7\%). These differences are heightened in the 252 advertisements where both male and female models are present, as males are even less likely to exhibit primarily masculine behavior (48\%) than any other gender role (including primarily feminine in 34\% of ads), whereas females continue to exhibit feminine behavior $(72 \%$, with only $5 \%$ classified as primary masculine).

\section{Female Roles}

In specifically examining the role that female models played in these advertisements, one of the most obvious absences in terms of female roles is that of the role of mother. Children are, for obvious reasons, never featured in cigarette advertising, so the cultural archetype of the mother was completely absent, and likewise were the aspects of that female experience that otherwise might have been shown - caring, achieving, etc. Simply stated, the first author found women to be relatively one-dimensional in these advertisements and that missing "motherhood" portrayal likely contributed to that.

Likewise, females are almost never seen as exhibiting any authority whatsoever regarding the product. Thus, the vast majority of advertisements featured a primary role for females of either a product user (simply smoking the cigarette which looking sensual) or as pure decoration (not even smoking at all, but just blatantly added into the advertisement to provide an element of attractiveness and/or sexuality to the advertisement). In the qualitative appraisal, the authors noted that females were more often portrayed in an incredibly objectified manner-as pure decoration-and even when they were a product user, they were oftentimes still treated largely as decoration.

Accordingly, in the 387 advertisements where females are present, the main female figure's primary role was never a family/mother-oriented one and rarely an authority on the product (2\%). Females were more often portrayed as product users $(34 \%)$, but significantly more often than users, they served a purely decorative role $\left(50 \%, \Pi^{2}(1)=11.33, p<.01\right)$. These roles are also consistent when males and females are together ( $26 \%$ product user, $51 \%$ purely decoration).

Model Size. In the pilot study, we deemed the images of males and females to be generally samesized, but it was noted that in several advertisements featuring both a male and female model where the female was purely decorative, they were often smaller than the male model. The male model seemed to be shown as larger to attract attention to the advertisement viewing male target audience (e.g., "you could be like him") and then secondarily the women (often sexually objectified) would be present in a smaller portion of the absolute space of the advertisement, offering up a promise that "if you WERE like him, you could have her."

Quantitative findings supported this observation. The 252 advertisements featuring both male and female models were much more likely to feature the main male and female models at equivalent size $(79 \%)$, with only $13 \%(8 \%)$ featuring a larger (smaller) male than female $\left(\Pi^{2}(2)=241.14, p<.001\right)$. However, in the 130 ads where at least one male and female model is present and the female role is described as purely decorative, more advertisements feature a larger male and smaller female (21\%) than a larger female and smaller male $(5 \%),\left(\Pi^{2}(1)=11.77, p<.01\right)$. 


\section{Model Interaction with Cigarettes}

In the qualitative analysis, it quickly became apparent that male and female models interacted differently with cigarettes. Men often actively held cigarettes in their mouths when performing an activity (e.g., playing pool, riding a horse), socializing, or just "hanging out." They were featured both smoking them (especially Joe Camel and the Marlboro Men) and also often lighting them up.

Women, on the other hand, so infrequently had cigarettes in their mouths that it became quite noticeable when they did (e.g., a female suggestively straddling a male in a car, cigarette in her mouth, in a Winston ad). Generally, women, in the rare occasions when they interacted with them, held cigarettes (or a pack) in their hand. Also, compared to the active portrayal of men, the women were more often represented as passive objects of sexual desire/beauty captured in time while active male subjects are going about living their enjoyable lives.

In order to quantitatively determine any gender differences in terms of models' interaction with cigarettes, we first examined the 256 advertisements that featured only males and the 131 advertisements that featured only females. In male-only ads, $22 \%$ showed a model with a cigarette in the mouth, compared to only $2 \%$ in female-only ads $\left(\Pi^{2}(1)=30.1, p<.001\right)$. Male only ads were also more likely to show a model lighting his or someone else's cigarette $\left(8 \%\right.$ of ads vs. $1 \%$ of female-only ads; $\Pi^{2}(1)=$ $8.39, p<.05)$. Conversely, ads featuring only females were more likely to show a cigarette in a model's hand $(46 \%)$ than male-only ads were $(33 \%),\left(\Pi^{2}(1)=5.87, p<.05\right)$ and females were more likely to have a cigarette pack in hand $\left(12 \%\right.$ of ads) than males $(4 \%)\left(\Pi^{2}(1)=8.40, p<.01\right)$. Overall, we find that male models were more likely than females to actually be smoking cigarettes, whereas female ad models were more likely to be holding them (single cigarette or a pack).

\section{Overall Advertising Themes}

In our Gestalt-type interpretation, cigarette advertisements seemed to be positioned more along the lines of hedonic messages (e.g., based on pleasure and sensation) than on utilitarian ones (e.g., based on function). However, this varied by brands. Marlboro and Camel advertisements, for instance, were positioned almost entirely along hedonic lines, attaching pleasurable lifestyles (e.g., the independent life of the Marlboro Man or the exciting life of Joe Camel) to their brands. Similarly, Newport and Parliament advertisements featured models engaged in enjoyable (and in the case of Newport, often humorous) activities. Other brands' positioning (Basic, for example), was centered much more around a utilitarian aspect of the brand (e.g., Basic's lower prices and no-nonsense image). Occasionally, ads also emphasized a new product attribute (e.g., both Winston and Salem featured advertisements touting cigarette package design improvements).

However, the overall impression from the Gestalt analysis was that models (especially women, and, particularly, sexualized women) were much more present in the hedonic-themed ads than in the utilitarian ones. The sexual, objectified female was offered as evidence of the hedonic potential offered to male users of the cigarette brand, whereas when a product claim or innovation was introduced there was no need for a model. It was an interesting observation that because cigarette brands did not generally "need" models in these utilitarian-themed advertisements, it even further restricted females to the more sexuallythemed hedonic advertisements and highlighted those aspects even more. In other words, if an entire portion of utilitarian advertisements feature the product only, and no models, there is less of a chance for those that do feature models to offer up the chance for those models to exhibit anything other than pleasure-seeking behavior. Given that this behavior is often sexual in nature targeted at men, using women, it restricts even further the female experience as shown in these aggregate advertisements.

This theme was confirmed quantitatively -- in advertisements where models are not present $(\mathrm{n}=210)$, advertisements are nearly as likely to feature a primarily utilitarian product meaning (41\%) as a primarily hedonic one (51\%; 8\% were classified as high on both). A subsequent chi-square test on the 192 modelless advertisements coded as either primarily hedonic or primarily utilitarian confirmed this equal likelihood statistically $\left(\Pi^{2}(1)=2.52\right.$, NS)). However, when models were present, advertisements were much more likely to be hedonic in nature than utilitarian $\left(\Pi^{2}(4)=20.55, p<.001\right)$, with $77 \%(75 \%, 88 \%)$ of advertisements featuring only male (only female, both male and female) models classified as primarily 
hedonic. A similar pattern emerged when viewing advertisements with other model presence levels; for instance, advertisements that featured only one male $(\mathrm{n}=166)$, only one female $(\mathrm{n}=118)$, or a malefemale dyad $(n=129)$ were much more likely to be classified as primarily hedonic $\left(\Pi^{2}(4)=25.16, p<\right.$ $.001)$ and the splits were similar to the above $(74 \%, 72 \%, 92 \%$ classified as primarily hedonic, respectively).

\section{DISCUSSION AND AREAS FOR FURTHER RESEARCH}

In sum, our content analysis of a decade's (1994-2003) worth of tobacco advertising suggests that the portrayal of females in male-targeted cigarette print advertising was largely and unabashedly designed to appeal to young, heterosexual male consumers. In aggregate, this imagery overwhelmingly objectifies the female gender; ads consisted of young, physically attractive, highly sexualized women whose purpose is largely decorative, primarily to endow the advertising with sexual attractiveness (e.g., through suggestive clothing) (Mayer and Baek, 2015). In the current study, we further find that they are assigned severely restrictive gender roles (rarely straying from traditional notions of femininity), are rarely featured in groups, and also exhibit less obvious differences (model size, interaction with cigarettes) that suggest pervasive differences vis-a-vis male model portrayals. These differences are often used to highlight that females are, quite simply, to be "decoration only;" with the heterosexual male gaze strongly on that limited portrayal, driving favorable associations and resulting attitudes for the brand while potentially also driving negative associations and learning about women. And for women who might be exposed to these advertisements or to the potentially resulting expectations of adult males who consumed them for a decade, there is quite simply an aggregate portrayal of them as physically attractive sexual objects where the key to getting a "cool" man is putting all effort into being as sexually attractive as possible. Put simply, these advertisements are both through the Gestalt analysis and quantitative lenses, highly objectifying of women.

Though this is a retrospective analysis, given that the use of sexual imagery in the post-MSA period from 1999-2003 was actually higher than the pre-MSA time period (Baek and Mayer, 2010), we suggest that this imagery is an important tool in cigarette advertisers' toolkit worldwide and one that should be monitored by stakeholders interested in the reduction of youth-oriented tobacco adoption and the reduction of objectifying portrayals of women in mainstream media. The use of sexual imagery is an executional element that could be used in virtually any advertising medium and it is certainly worth examining whether the trends we present in this analysis have continued in the past decade in areas of industry focus (e.g., new digital media) or with new products (e.g., e-cigarettes). One could argue that a flaw of the MSA was leaving sexual imagery as an acceptable advertising element in tobacco advertisements, and that policymakers both in the United States and especially in countries moving towards similar bans, would be advised to restrict this advertising element.

In today's American advertising and media environment, we see the impact that public discourse and transparency can have (e.g., the \#metoo movement) in terms of bringing some of the experience of American females to light versus simply assuming that things are "the way they are." It is our hope that by shining a light specifically on a small piece of the advertising environment of recent yesteryear through this research project, we can provide both qualitative and quantitative evidence of the pervasiveness of objectification that can occur in the media.

Oftentimes, advertisers with a predominantly male consumer target are faced with the question of "what executional element should I use to best achieve brand recognition, recall, and/or sales." Regarding the connection of female sexualization to female objectification, Fasoli et al. (2018) found that increasing the levels of sexualization in photos made it more likely that participants would interpret the models as sexual objects - the aggregate effect of these images is likely to have had a profound, negative effect on females in America. This study illustrates that when the individual answer to that question is the use of objectified females, over time it can metaphorically turn from individual raindrops to a flood that may have deleterious effects on both the objectified female and, potentially, on the advertised-to male. 


\section{REFERENCES}

Allen, M., Emmers, T., Gebhardt, L., \& Giery, M. A. (1995). Exposure to pornography and acceptance of rape myths. Journal of Communication, 45(1), 5-26.

APA Task Force on the Sexualization of Girls. (2007, January 1). Report of the APA Task Force on the Sexualization of Girls. Retrieved November 29, 2010, from http://www.apa.org/pi/women/programs/girls/report

Baek, T.H., \& Mayer, J.M. (2010). Sexual imagery in cigarette advertising before and after the Master Settlement Agreement. Health Communication, 25(8), 747-57.

Baker, C.N. (2005). Images of Women's Sexuality in Advertisements: A Content Analysis of Black- and White-Oriented Women's and Men's Magazines. Sex Roles, 52(1-2), 13-27.

Belk, R.W. (1987). Material Values in the Comics: A Content Analysis of Comic Books Featuring Themes of Wealth. Journal of Consumer Research, 14(1), 26-42.

Belk, R.W., \& Pollay, R.W. (1985). Images of Ourselves: The Good Life in Twentieth Century Advertising. Journal of Consumer Research, 11(4), 887-97.

Bem, S.L. (1974). The Measurement of Psychological Androgyny. Journal of Consulting and Clinical Psychology, 42(2), 155-62.

Courtney, A.E., \& Lockeretz, S.W. (1971, February). A Woman's Place: An Analysis of the Roles Portrayed by Women in Magazine Advertisements. Journal of Marketing Research, 8, 92-5.

Courtney, A.E., \& Whipple, T.W. (1974, June). Women in T. V. Commercials. Journal of Communication, 24, 110-8.

Fasoli, F., Durante, F., Mari, S., Zogmaister, C., \& Volpato, C. (2018). Shades of sexualization: When sexualization becomes sexual objectification. Sex Roles, 78(5), 338-351. doi:10.1007/s11199017-0808-1

Ferguson, J.H., Kreshel, P.J., \& Tinkham, S.F. (1990). In the Pages of Ms.: Sex Role Portrayals of Women in Advertising. Journal of Advertising, 19(1), 40-51.

Ford, J.B., Voli P.K., Honeycutt, E.D., \& Casey, S.L. (1998). Gender Role Portrayals in Japanese Advertising: A Magazine Content Analysis. Journal of Advertising, 27(1), 113-24.

Fredrickson, B., \& Roberts, T. (1997). Objectification theory - toward understanding women's lived experiences and mental health risks. Psychology of Women Quarterly, 21(2), 173-206. doi:10.1111/j.1471-6402.1997.tb00108.x

Gilly, M.C. (1988). Sex Roles in Advertising: A Comparison of Television Advertisements in Australia, Mexico, and the United States. Journal of Marketing, 52(2), 75-85.

Goffman, E. (1976). Gender Advertisements. Cambridge, MA: Harvard University Press.

Holbrook, M.B. (1987). Mirror, Mirror on the Wall, What's Unfair in the Reflections on Advertising? Journal of Marketing, 51(3), 95-103.

King, K.W., Reid, L.N., \& Becham, A.L. (1994). Themes and Verbal Claims in Cigarette and Alcohol Beverage Ads. Journal of Current Issues \& Research in Advertising, 16(2), 73-88.

King, K.W., Reid, L.N., Moon, Y.S., \& Ringold, D.J. (1991). Changes in the Visual Imagery of Cigarette Ads, 1954-1986. Journal of Public Policy \& Marketing, 10(1), 63-80.

Kolbe, R.H., \& Albanese, P.J. (1996). Man to Man: A Content Analysis of Sole-Male Images in MaleAudience Magazines. Journal of Advertising, 25(4), 1-20.

Lundstrom, W.J., \& Sciglimpaglia, D.M. (1977). Sex Role Portrayals in Advertising. Journal of Marketing, 41(3), 72-9.

Malamuth, N. M. (1984). Aggression against women: Cultural and individual causes. In N.M. Malamuth \& E. Donnerstein (Eds.), Pornography and sexual aggression. Orlando, FL: Academic Press.

Mayer, J.M., \& Baek, T.H. (2015). The Efficacy of Sexualized Female Models in Young Adult Male Oriented Cigarette Advertising. Developments in Marketing, 12, 484-95.

McArthur, L.Z., \& Resko, B.G. (1975, December). The Portrayal of Men and Women in American T. V. Commercials. Journal of Social Psychology, 97, 209-20. 
Perreault, W.D. Jr., \& Leigh, L.E. (1989), Reliability of Nominal Data Based on Qualitative Judgments. Journal of Marketing Research, 26, 135-48.

Pingree, S., Hawkins, R.P., Butler, M., \& Paisley, W. (1976, December). A Scale for Sexism. Journal of Communication, 26, 193-200.

Pollay, R.W. (1986). The Distorted Mirror: Reflections on the Unintended Consequences of Advertising. Journal of Marketing, 50, 18-36.

Pollay, R.W., Siddarth, S., Siegel, M., Haddix, A., Merritt, R.K., Giovino, G.A., \& Eriksen, M.P. (1996, April). The Last Straw? Cigarette Advertising and Realized Market Shares Among Youths and Adults, 1979-1993. Journal of Marketing, 60, 1-16.

Reichert, T. (2003). The Erotic History of Advertising. Amherst, NY: Prometheus.

Reichert, T., \& Carpenter, C. (2004). An Update on Sex in Magazine Advertising: 1983 to 2003. Journalism and Mass Communication Quarterly, 81(4), 823-37.

Reichert, T., \& Ramirez, A. (2000). Defining Sexually Oriented Appeals in Advertising: A Grounded Theory Investigation. Advances in Consumer Research, 27(1), 267-73.

Riffe, D., Lacy, S., \& Fico, F.G. (1998). Analyzing Media Messages:Using Quantitative Content Analysis in Research. Mahwah, NJ: Lawrence Erlbaum Associates.

Rust, R.T., \& Cooil, B. (1994). Reliability Measures for Qualitative Data: Theory and Implications. Journal of Marketing Research, 31, 1-14.

Sebastian, M. (2013). Camel Cigarettes Return to Print Ads. Advertising Age. Retrieved from www.adage.com 5/13/13.

Sexton, D.E., \& Haberman, P. (1974). Women in Magazine Advertisements. Journal of Advertising Research, 14(4), 41-6.

Soley, L., \& Kurzbard, G. (1986). Sex in Advertising: A Comparison of 1964 and 1984 Magazine Advertisements. Journal of Advertising, 15(3), 46-54.

Sung, Y., \& Hennink-Kaminski, H. (2008). The Master Settlement Agreement and Visual Imagery of Cigarette Advertising in Two Popular Youth Magazines. Journalism \& Mass Communication Quarterly, 85(2), 331-52.

Vandenbosch, L., \& Eggermont, S. (2012). Understanding sexual objectification: A Comprehensive approach toward media exposure and girls' internalization of beauty ideals, self-objectification, and body surveillance. Journal of Communication, 62(5), 869-887.

Venkatesan, M., \& Losco, J. (1975). Women in Magazine Ads: 1959-71. Journal of Advertising Research, 15(5), 49-54.

Voss, K.E., Spangenberg, E.R., \& Grohmann, B. (2003). Measuring the Hedonic and Utilitarian Dimensions of Consumer Attitude. Journal of Marketing Research, 40(3), 310-20. 


\section{APPENDIX \\ CONSTRUCT OPERATIONAL DEFINITIONS}

Sex and Presence of Human Models

The number of human models of each sex that appeared in the ad.

Sex Role Portrayal (adapted from Bem 1974)

Over time, researchers have identified behaviors that are strongly associated with masculinity and ones that are strongly associated with femininity. Traditional gender roles suggest that men will exhibit the masculine ones, and women will exhibit the feminine ones. But these traits are not mutually exclusive - a person can be both highly masculine and feminine, or much more one than the other, or very low on both.

The Bem Sex Roles Inventory (BSRI) is a scale that's been widely used in classifying gender. Raters classified the behavior of the models in the advertisements along these masculine-feminine lines, comparing model's portrayals to traditional descriptors associated with each behavior:

$\underline{\text { Masculine }}$

Acts as leader, Aggressive, Ambitious, Analytical, Assertive, Athletic, Competitive, Defends Own Beliefs, Dominant, Forceful, Has leadership abilities, Independent, Individualistic, Makes decisions easily, Masculine, Self-Reliant, Self-Sufficient, Strong Personality, Willing to take a stand, Willing to take risks. Feminine

Affectionate, Cheerful, Childlike, Compassionate, Does not use harsh language, Eager to soothe hurt feelings, Feminine, Flatterable, Gentle, Gullible, Loves Children, Loyal, Sensitive to the needs of others, Shy, Soft Spoken, Sympathetic, Tender, Understanding, Warm, Yielding.

The main male model and the main female model were classified as exhibiting one of four combinations of masculinity and femininity:

- Highly masculine (with low femininity)?

- Highly feminine (with low masculinity)?

- High on both masculinity and femininity?

- Low on both masculinity and femininity?

Female Model Role Portrayal (adapted from Baker 2005 and Ford et al. 1998)

Coders identified the primary role of the main female model in advertisements as:

1. Product Authority A character may be presented as an authority on the product, perhaps providing a recommendation that this is the product a consumer should choose.

2. Product User Another purpose might be that the model is a product user, shown using the product in an appropriate setting in order to appeal to the consumer.

3. Family Role

4. Decorative Role The model may be portrayed in a family role, like being a mother.

The model may have a purely decorative function; that is, they are simply there to look good and by association help make the product look good. They serve no function other than looking attractive

5. Other The model's role is not expressed in choices 1-4.

Relative Size of Female Model as Compared to Male Model (adapted from Baker 2005)

Coders noted the relative size of the main female versus the main male model in the ads is, not in terms of physical stature (e.g., how much does the model weigh?) but rather the amount of space in the advertisement that is dedicated to the models.

1. The woman is larger than the man: select this if the woman is taking up more of the ad space than the man.

2. The woman is smaller than the man: select this if the man is taking up more space than the woman.

3. The woman is of equal size to the man: select this if the woman and man take up about the same space. 


\section{Model Interaction with Cigarette}

1. Cigarette in hand of model(s)

2. Cigarette in mouth of model(s)

3. Pack in hand of model(s)

4. Model lighting cigarette for oneself and/or others

5. Other interaction with product not mentioned above (e.g., model offers a cigarette to viewers)

Hedonic / Utilitarian Theme (adapted from Voss et al. 2003)

Cigarette manufacturers can use many different message types in their advertisements to try and give the products and brands different meanings to consumers. One of the decisions they make is whether to use a more hedonic message, or a more utilitarian message.

1. Primarily hedonic: The American Heritage Dictionary (4th ed.) defines the word hedonic as "of, relating to, or marked by pleasure." A hedonic meaning, in the words of one researcher, is "resulting from sensations derived from the experience of using the product." This experience can be about the cigarette itself, or about the lifestyle, relationships, physical enjoyment, emotions, etc. that the models are experiencing. A cigarette could be bestowed with a hedonic meaning (pleasure, emotions, enjoyment, lifestyle, etc.),

2. Primarily utilitarian: A utilitarian meaning is about the utility that the product delivers; the same researcher writes that it is "derived from functions performed by products." This meaning is about how well the product does its "function." It could have utilitarian meaning (focusing on a product component; e.g., low tar).

3. Equally hedonic and utilitarian: It could have both components present. 